\title{
$\alpha$-Exomethylene lactone possessing acetal-ester linkage: Polymerization and post-polymerization modification for water-soluble polymer
}

\author{
Yasuhiro Kohsaka, ${ }^{1}$ Yusuke Matsumoto, ${ }^{2}$ Tianyi Zhang, ${ }^{2}$ Yosuke Matsuhashi, ${ }^{1}$ Tatsuki Kitayama ${ }^{2}$ \\ ${ }^{1}$ Faculty of Textile Science and Technology, Shinshu University, 3-15-1 Tokida, Ueda, Nagano 386-8567, \\ Japan \\ 2 Department of Chemistry, Graduate School of Engineering Science, Osaka University, 1-3 \\ Machikaneyama, Toyonaka, Osaka 560-8531, Japan
}

Correspondence to: Y. Kohsaka (E-mail: kohsaka@shinshu-u.ac.jp) or T. Kitayama (E-mail: kitayama@chem.es.osaka-u.ac.jp)

((Additional Supporting Information may be found in the online version of this article.))

\begin{abstract}
2,6-Dimethyl-5-methylene-1,3-dioxa-4-one (DMDO), a cyclic acrylate possessing acetal-ester linkage, was obtained as a mixture of cis- and trans-isomers (95:5) from Baylis-Hillman reaction of an aryl acrylate. The radical and anionic polymerizations of DMDO yielded the corresponding vinyl polymers without any side reactions such as cleavage of the acetal-ester linkage. The polymerization behaviors were significantly different from that of the acyclic acrylate, $\alpha$-(hydroxymethyl)acrylic acid, which was expected inactive against polymerization due to the steric hindrance around the vinylidene group by the $\alpha$-substituent. The acetal-ester linkage of the obtained polymer (P1) was completely cleaved via acid hydrolysis to afford a water soluble polymer, $\mathbf{P} \mathbf{2}$.
\end{abstract}

\section{INTRODUCTION}

$\alpha$-Exomethylene lactones (EMLs) are cyclic acrylates, which afford vinyl polymers via radical, $^{1-6}$ anionic, $^{1,7-11}$ and coordination polymerization $^{12-14}$ as an acrylate monomer as well as polyesters via ring-opening polymerization (ROP). ${ }^{15-18}$ In particular, EMLs with 5-membered ring such as $\alpha$-methylene- $\gamma$ butyrolactone (MBL), ${ }^{1,5-9,12,16} \alpha$-methylene- $\beta$ methyl- $\gamma$-butyrolactone ( $\beta M M B L),{ }^{4,7,9,10,12,13}$ and $\alpha$-methylene- $\gamma$-methyl- $\gamma$-butyrolactone $(\gamma \mathrm{MMBL})^{3,12,14}$ are known as renewable monomers from biomass products. Moreover, since their vinyl polymers exhibit higher glass transition temperatures $\left(T_{\mathrm{g}} \mathrm{s}\right)$ than a typical acrylic polymer, poly(methyl methacrylate) (PMMA), ${ }^{1,12}$ the polymerization of EMLs has gained much attention.
Recently, we have been interested in the polymerization chemistry of $\alpha$-functionalized acrylates, as the $\alpha$-functionality bound to the vinyl groups leads to unique polymerization behaviors that facilitate the controls of endfunctionality $^{19-23}$ and monomer sequence ${ }^{24}$ as well as the excellent polymer properties such as fluorescence $^{24}$ and $\mathrm{pH} /$ temperatureresponsiveness. ${ }^{25}$ Along the line of this concept, herein, we have designed a new monomer, i.e. an $\alpha$-functionalized acrylates which has a feature of EMLs possessing acetal-ester (A-E) linkage in its lactone skeleton. Among them, a simple example, 2,6-dimethyl-5-methylene-1,3dioxa-4-one (DMDO) can be synthesized via Bailys-Hilman reaction of phenyl acrylate, ${ }^{26,27}$ but no application in polymer chemistry are reported. As well known, A-E linkage is a dynamic covalent bond, which is readily converted to carboxyl and hydroxyl groups by 
acid hydrolysis, while the thermal decomposition affords a carboxylic acid and a vinyl ether. ${ }^{28-30}$ In fact, polymers with $A-E$ linkage in their side groups ${ }^{28,29}$ and backbones ${ }^{30}$ have been reported as degradable polymeric materials. Similarly, DMDO is expected to afford water-soluble polymer (P2) with hydroxyl and carboxylic groups in the pendant groups via vinyl polymerization followed by acid hydrolysis (Scheme 1), while the ROP may result a degradable polyester. Among the two different types of polymerization, this paper describes the vinyl polymerization and the postpolymerization modification of DMDO. A unique polymerization behavior distinctive from the corresponding acyclic acrylate monomer is also discussed.

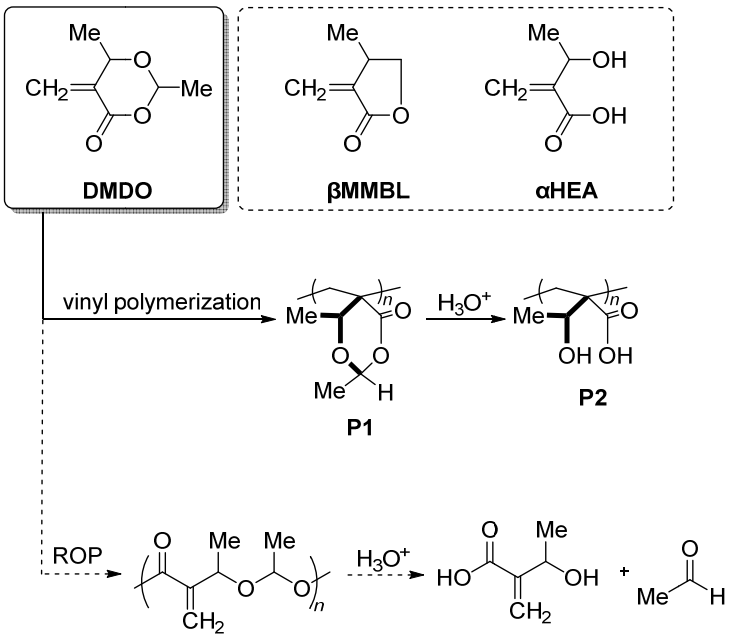

SCHEME 1 Structure and polymerization of DMDO.

\section{EXPERIMENTAL}

\section{Materials}

Acryloyl chloride was provided by the Iharanikkei Chemical Industry Co., Ltd. 2,2'Azobisisobutyronitrile (AIBN) (Wako) was recrystallized from ethanol. $\mathrm{CH}_{2} \mathrm{Cl}_{2}$ (Wako, super dehydrated grade) was dried over $\mathrm{CaH}_{2}$ and distilled under high vacuum just before use. Isopropyl $\alpha$-lithioisobutyrate (Li-iPrIB) was prepared and recrystallized in toluene according to our previous report. ${ }^{31}$ Other chemicals were used as purchased without further purification.

\section{Instruments}

${ }^{1} \mathrm{H}$ and ${ }^{13} \mathrm{C}$ NMR spectra were recorded in $\mathrm{CDCl}_{3}$ (Aldrich) and DMSO- $d_{6}$ (Aldrich) on a Unity Inova 500 (Varian) spectrometer or an ECS-400 spectrometer (JEOL). Chemical shifts in ${ }^{1} \mathrm{H} N M R$ spectra were referred to the signal of tetramethylsilane (TMS) or solvent peaks. IR spectra were recorded on an FT/IR-410 Fouriertransform infrared spectrometer (JASCO). Molecular weights and its distributions of the polymers were determined at $40{ }^{\circ} \mathrm{C}$ by sizeexclusion chromatography (SEC) using a GPC900 chromatograph (JASCO) equipped with two SEC columns [Polymer Laboratories, PL-gel, Mixed C (300 mm $\times 7.5 \mathrm{~mm})$ ] and a differential refractometer installed in the system, using tetrahydrofuran (THF) as an eluent, and calibrated against standard PMMA samples (Shodex, MW: $1.25 \times 10^{6}, 6.59 \times 10^{5}, 1.95 \times 10^{5}$, $4.96 \times 10^{4}, 2.06 \times 10^{4}, 6.82 \times 10^{3}, 2.00 \times 10^{3}$ ). Samples were loaded as THF solutions $\left(1 \mathrm{~g} \mathrm{~L}^{-1}\right.$, $100 \mu \mathrm{L})$. Purities of terminating agents were determined from the gas chromatogram (GC) recorded on a GC-2014 (Shimadzu) equipped with a HP-5 capillary column (Hewlett-Packard). $5 \%$ Weight-loss temperature $\left(T_{\mathrm{d} 5}\right)$ was determined from thermogravimetry / differential thermal analysis (TG/DTA) performed with an EXSTAR TG6000/DTA6200 (SII NanoTechnology) (scan rate $=10{ }^{\circ} \mathrm{C} \mathrm{min}{ }^{-1}$ ) under $\mathrm{N}_{2}$ atmosphere (flow rate $=100 \mathrm{~mL} \mathrm{~min}^{-1}$ ). Glass transition temperature $\left(T_{\mathrm{g}}\right)$ was determined from differential scanning calorimetry (DSC) performed with an EXSTAR DSC6000.

\section{Synthesis}

\section{4-(1,1,3,3-tetramethylbutyl)phenyl acrylate (3)}

To a solution of 4-(1,1,3,3-tetramethylbutyl)phenol (12.4 g, $60.0 \mathrm{mmol}$ ) and $\mathrm{Et}_{3} \mathrm{~N}(9.2$ $\mathrm{mL}, 66 \mathrm{mmol})$ in $\mathrm{CH}_{2} \mathrm{Cl}_{2}(60 \mathrm{~mL})$ was added dropwise acryloyl chloride $(5.3 \mathrm{~mL}, 66 \mathrm{mmol}$ ) over $30 \mathrm{~min}$ at $0{ }^{\circ} \mathrm{C}$. After $3 \mathrm{~h}$, the reaction 
mixture was quenched with water $(30 \mathrm{~mL})$. The organic layer was washed with sat. $\mathrm{NaHCO}_{3}$ aq (30 mL), dried over $\mathrm{Na}_{2} \mathrm{SO}_{4}$, and concentrated. The residue was dried in vacuo to afford 3 (14.7 g) as yellow viscous oil. The product was used without further purification. Purity (GC): $97.1 \%$; Yield: 94.2\%; ${ }^{1} \mathrm{H} \mathrm{NMR}\left(400 \mathrm{MHz}, \mathrm{CDCl}_{3}, 30{ }^{\circ} \mathrm{C}\right.$, ठ): 7.38-7.25 (m, 2H, 2/6-H), $7.04\left(\mathrm{dd}, 2 \mathrm{H}, J_{1}=\right.$ $\left.3.6 \mathrm{~Hz}, J_{2}=2.0 \mathrm{~Hz}, 3 / 5-\mathrm{H}\right), 6.58\left(\mathrm{dd}, 1 \mathrm{H}, J_{1}=19\right.$ $\left.\mathrm{Hz}, J_{2}=1.2 \mathrm{~Hz}, \mathrm{CH}_{\text {cis }} \mathrm{H}\right), 6.31\left(\mathrm{dd}, 1 \mathrm{H}, J_{1}=19 \mathrm{~Hz}\right.$, $\left.J_{2}=2.0 \mathrm{~Hz}, \mathrm{CH}\right), 5.98\left(\mathrm{dd}, 1 \mathrm{H}, J_{1}=12 \mathrm{~Hz}, J_{2}=1.2\right.$ $\left.\mathrm{Hz}, \mathrm{CH}_{\text {trans }}\right), 1.73\left(\mathrm{~s}, 2 \mathrm{H}, \mathrm{CH}_{2}\right), 1.37(\mathrm{~s}, 6 \mathrm{H}, 1-$ $\left.\mathrm{CH}_{3}\right), 0.73\left(\mathrm{~s}, 9 \mathrm{H}, 3-\mathrm{CH}_{3}\right) \mathrm{ppm}$.

\section{2,6-dimethyl-5-methylene-1,3-dioxa-4-one (DMDO)}

To a mixture of 1,4-diazabicyclo[2.2.2]octane (DABCO) (2.80 g, $25.0 \mathrm{mmol}$ ) and acetaldehyde (90 wt\% in water, $76.0 \mathrm{~mL}, 1.25 \mathrm{mmol}$ ) was added dropwise 3 (70.1 g, $250 \mathrm{mmol})$. After 21 $\mathrm{h}$, the complete consumption of $\mathbf{3}$ was observed by GC, and then water $(300 \mathrm{~mL})$ was added. The product was extracted with hexane $(300 \mathrm{~mL} \times$ 2). The organic layer was dried over $\mathrm{Na}_{2} \mathrm{SO}_{4}$ and concentrated. The product was purified by distillation under reduced pressure $\left(40{ }^{\circ} \mathrm{C} / 0.20\right.$ $\mathrm{mmHg}$ ) to yield DMDO (14.0 g, yield $39.4 \%$, purity 99.7\%) as a colorless oil. ${ }^{1} \mathrm{H} N M R$ $\left(400 \mathrm{MHz}, \mathrm{CDCl}_{3}, 30{ }^{\circ} \mathrm{C}, \delta\right): 6.51$ (d, $J=2.3 \mathrm{~Hz}$, $0.95 \mathrm{H}$, cis-b), $6.47(\mathrm{~d}, J=2.3 \mathrm{~Hz}, 0.05 \mathrm{H}$, trans-b), $5.61(\mathrm{~d}, J=2.3 \mathrm{~Hz}, 1 \mathrm{H}, \mathrm{a}), 5.51$ (quart, $J=5.3 \mathrm{~Hz}$, $1 \mathrm{H}, \mathrm{e}), 4.92-4.87(\mathrm{~m}, 0.05 \mathrm{H}$, trans $-\mathrm{d}), 4.68-4.62$ (m, $0.95 \mathrm{H}$, cis-d), 1.52 (d, J = 5.3 Hz, 3H, f), 1.49 (d, $J=6.4 \mathrm{~Hz}, 3 \mathrm{H}, \mathrm{c}$ ) ppm (for assignments, see Figure 1); ${ }^{13} \mathrm{C} \mathrm{NMR}\left(100 \mathrm{MHz}, \mathrm{CDCl}_{3}, 30{ }^{\circ} \mathrm{C}, \delta\right)$ : $163.2(\mathrm{C}=\mathrm{O}), 137.7\left(\mathrm{CH}_{2}=\right), 125.5(=\mathrm{C}<), 99.5$ (OCO), 74.1 (=CCO), 20.9 (Me), 20.3 (Me) ppm.

\section{Radical polymerization}

A typical procedure is as follows (Table 1, Run 1). In a glass test tube, a mixture of DMDO (569 mg, $4.00 \mathrm{mmol}$ ) and AIBN (33 mg, $0.20 \mathrm{mmol}$ ) was dissolved in toluene $(4.0 \mathrm{~mL})$ and the reaction mixture was degassed using a freeze-pumpthaw cycle three times. Nitrogen gas was then introduced into the test tube and the reaction mixture was heated at $60{ }^{\circ} \mathrm{C}$ for $12 \mathrm{~h}$. A small portion of the reaction mixture was sampled to estimate the conversion. The reaction mixture was then poured into hexane $(200 \mathrm{~mL})$ and the precipitate was collected, washed with hexane, and dried in vacuo to give a polymer, P1 (311 $\mathrm{mg})$, as a white solid. The sampled reaction mixture was dissolved in $\mathrm{CDCl}_{3}$ and the ${ }^{1} \mathrm{H} \mathrm{NMR}$ spectra recorded. The conversion of DMDO was estimated from the integral ratio of the signal of the vinylidene group to others. In Runs 2-4, a small amount of bis(trimethylsilyl)acetylene was mixed with the reaction mixture as an internal standard to determine the conversions for cis and trans isomers.

\section{Anionic polymerization}

A typical procedure is as follows (Table 1, Run 6 ): To a glass ampoule filled with dried $\mathrm{N}_{2}$ gas passed through molecular sieves $4 \mathrm{~A}$ cooled at $78{ }^{\circ} \mathrm{C}, \mathrm{CH}_{2} \mathrm{Cl}_{2}(5.0 \mathrm{~mL})$, and Li-iPrIB (0.25 mmol) were added at room temperature using hypodermic syringes. The reaction mixture was cooled to $0{ }^{\circ} \mathrm{C}$, and the polymerization was started by adding DMDO (5.0 mmol). After $12 \mathrm{~h}$, methanol $(1 \mathrm{~mL})$ was added and then the polymer was recovered by precipitation with hexane $(200 \mathrm{~mL})$, filtered and washed with hexane, acidic water and water, successively, and dried in vacuo at $40{ }^{\circ} \mathrm{C}$ to give a polymer, P1 (613 mg) as a white solid.

\section{Acid hydrolysis of P1}

P1 (71.2 $\mathrm{mg}, 0.500 \mathrm{mmol} / \mathrm{unit}$ ) were added into DMSO- $d_{6}(0.60 \mathrm{~mL})$, and a small amount of $1 \mathrm{M}$ $\mathrm{HCl}$ aq solution (ca. $0.10 \mathrm{~mL}$ ) was added. The opaque mixture was heated at $50{ }^{\circ} \mathrm{C}$ with monitoring the reaction proceedings by ${ }^{1} \mathrm{H} N M R$ spectroscopy. After $5 \mathrm{~h}$, the signals from acetaldehyde were observed at $2.11\left(\mathrm{CH}_{3}\right)$ and $9.64(\mathrm{CHO}) \mathrm{ppm}$. After $30 \mathrm{~h}$, the signals of $2-\mathrm{CH}$ (5.51 ppm) and 2- $\mathrm{CH}_{3}$ (1.44 ppm) completely disappeared. Then, the mixture was cooled to room temperature and poured into $\mathrm{Et}_{2} \mathrm{O}(30$ $\mathrm{mL}$ ) to recover the polymer. After removing the solvent, the precipitation was dried at 50 ${ }^{\circ} \mathrm{C}$ under vacuum (40.0 $\mathrm{mg}, 81.3 \%$ yield). 


\section{Conformational search by molecular mechanics}

Stable conformations of cis- and trans-DMDO were searched by molecular mechanics (MM) by MacroModel 9.9 operated on Maestro ver. 9.3.5 included in Schrödinger Suite 2012. The calculations were performed with Intel Core i5$3337 \mathrm{U}(1.80 \mathrm{GHz})$ processor. For calculations, the chemical structure built up on ChemBioDraw 3D (PerkinElmer) was optimized on OPLS_2005 force field in no solvent by gradient method (iterations: 5000 , convergence threshold: 0.05). Then, stable conformations were searched on the force field with Mixed torsional / Low-mode sampling method (iterations: 500, convergence threshold: 0.05, Energy window for saving structures: $50 \mathrm{~kJ} \mathrm{~mol}^{-1}$ ). Finally, the searched conformations were optimized again.

\section{RESULTS AND DISCUSSION}

\section{Synthesis of DMDO}

According to the literature, DMDO was prepared through the Baylis-Hillman reaction between phenyl acrylate and acetaldehyde. ${ }^{26,27}$ Since the liberated phenol has similar polarity and boiling point with DMDO, however, the purification was found troublesome. Then, 4(1,1,3,3,-tetramethylbutyl)phenyl acrylate (3), which could be prepared the commercially available phenol, was selected as a staring material (Scheme 2) after several trials (See supporting information). The much higher boiling point of the liberated $4-(1,1,3,3,-$ tetrametylbutyl)phenol allowed facile purification by distillation to afford DMDO with high purity (99.7\%). Since DMDO has two chiral centers, it was obtained as a mixture of two pairs of enantiomers and diastereomers. In order to determine the stereochemistry, differential nuclear Overhauser effect (NOE) ${ }^{1} \mathrm{H}$ NMR spectra were measured as well as normal ${ }^{1} \mathrm{H}$ NMR measurement (Figure 1). The irradiation at $5.51 \mathrm{ppm}(6-\mathrm{CH}$ signal, e) resulted in NOEs at 4.68-4.62 ppm (2-CH signal, d, 0.9\%) and at $1.52 \mathrm{ppm}$ (6-Me signal, c, 0.9\%, Figure 1b). The former indicates that the protons assignable to the stronger signal between a set of signal $d$ at 4.68-4.62 ppm and 4.92-4.87 ppm is close to $6-\mathrm{CH}$ group, that is, cis-isomer. It is also confirmed that no distinct NOE was found at $5.51 \mathrm{pm} \mathrm{(6-}$

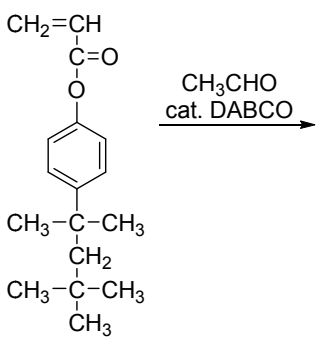

3

SCHEME 2 Synthesis of DMDO.

(c)

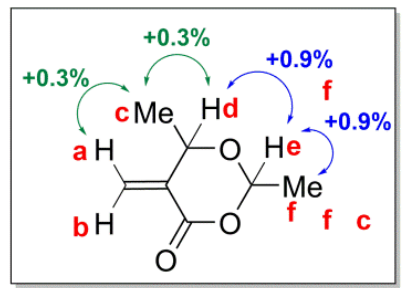

a d

(b)

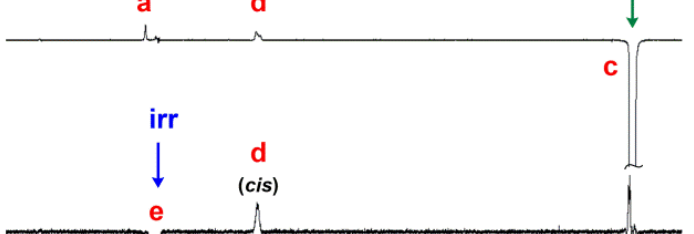

(a)

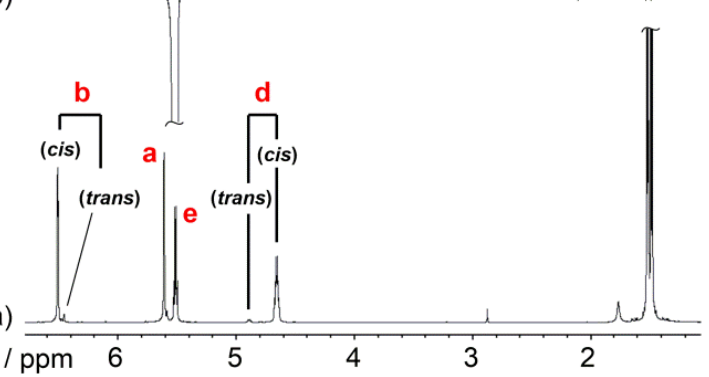

FIGURE 1 (a) ${ }^{1} \mathrm{H}$ NMR spectrum of DMDO and its differential NOE spectra irradiated at (b) 5.51 ppm and (6-CH, e) (c) $1.52 \mathrm{ppm}(6-\mathrm{Me}, \mathrm{c})(500$ $\left.\mathrm{MHz}, \mathrm{CDCl}_{3}, 30^{\circ} \mathrm{C}\right)$.

$\mathrm{CH}$ signal, e) when a pulse was irradiated at 1.49 pm (2-Me, signal, c, Figure 1c). Consequently, the split ${ }^{1} \mathrm{H}$ NMR signals of proton $\mathrm{b}$ (6.51 and $6.47 \mathrm{ppm})$ and $\mathrm{d}$ (4.68-4.62 ppm and 4.92-4.87 ppm) can be assigned as 
TABLE 1 Radical and anionic polymerizations of DMDO.

\begin{tabular}{|c|c|c|c|c|c|c|c|c|c|c|c|c|c|c|c|}
\hline \multirow[t]{2}{*}{ Run } & \multirow{2}{*}{$\begin{array}{l}\mathrm{DMDO} \\
(\mathrm{mmol})\end{array}$} & \multirow[t]{2}{*}{ Initiator } & \multirow{2}{*}{$\begin{array}{l}{[\mathrm{DMDO}]_{0} /} \\
{[\text { Initiator }]_{0}}\end{array}$} & \multicolumn{2}{|c|}{ Solvent (mL) } & \multirow{2}{*}{$\begin{array}{l}\text { Temp. } \\
\left({ }^{\circ} \mathrm{C}\right)\end{array}$} & \multirow{2}{*}{$\begin{array}{l}\text { Time } \\
\text { (h) }\end{array}$} & \multicolumn{3}{|c|}{ Conversion (\%) ${ }^{\mathrm{a}}$} & \multirow{2}{*}{$\begin{array}{l}\text { Yield }^{b} \\
(\%)\end{array}$} & \multirow[t]{2}{*}{$M_{\mathrm{n}}^{\mathrm{c}}$} & \multirow[t]{2}{*}{$M_{\mathrm{w}} / M_{\mathrm{n}}^{\mathrm{c}}$} & \multirow{2}{*}{$\begin{array}{l}T_{\mathrm{d} 5} \\
\left({ }^{\circ} \mathrm{C}\right)^{\mathrm{d}}\end{array}$} & \multirow{2}{*}{$\begin{array}{l}T_{\mathrm{g}} \\
\left({ }^{\circ} \mathrm{C}\right)^{\mathrm{e}}\end{array}$} \\
\hline & & & & & & & & Total & cis & trans & & & & & \\
\hline 1 & 4.0 & AIBN & $20 / 1$ & Toluene & $(4.0)$ & 65 & 24 & 60 & & & 55 & 2520 & 2.04 & 206 & 10.1 \\
\hline 2 & 4.0 & AIBN & $100 / 1$ & Toluene & $(2.0)$ & 60 & 17 & 52 & 53 & 33 & 42 & $18500^{f}$ & $2.25^{\mathrm{e}}$ & & \\
\hline 3 & 4.0 & AIBN & $50 / 1$ & None & & 60 & 17 & 69 & 71 & 32 & 68 & 27000 & 3.96 & & \\
\hline 4 & 4.0 & $\mathrm{DTBP}^{\mathrm{g}}$ & $50 / 1$ & None & & 110 & 17 & 77 & 78 & 49 & 78 & 14000 & 3.93 & & \\
\hline 5 & 5.0 & Li-IPrlB & $20 / 1$ & $\mathrm{CH}_{2} \mathrm{Cl}_{2}$ & $(5.0)$ & -78 & 18 & & & & 21 & 2800 & 1.91 & & \\
\hline 6 & 5.0 & Li-IPrIB & $20 / 1$ & $\mathrm{CH}_{2} \mathrm{Cl}_{2}$ & $(5.0)$ & 0 & 18 & 94 & & & 82 & 2500 & 2.15 & & 9.3 \\
\hline
\end{tabular}

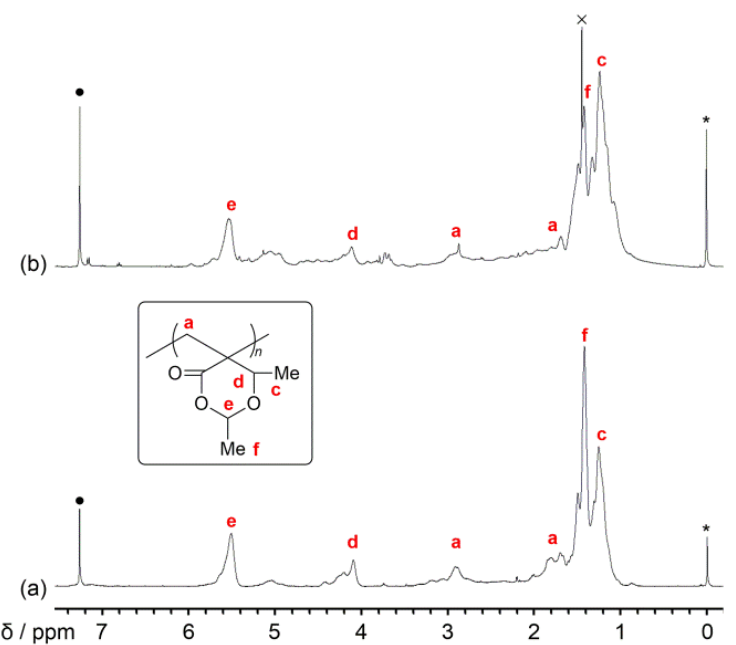

FIGURE $2{ }^{1} \mathrm{H}$ NMR spectra of P1 prepared from (a) radical and (b) anionic polymerizations (500 $\left.\mathrm{MHz}, \mathrm{CDCl}_{3}, 30^{\circ} \mathrm{C}\right) \cdot \bullet: \mathrm{CHCl}_{3}, \times: \mathrm{H}_{2} \mathrm{O},{ }^{*}: \mathrm{Me}_{4} \mathrm{Si}$.

described in Figure 1a. From the intensity ratio of signal $d$, the composition of cis- and transisomers was determined as $95: 5$. This tendency agrees with the reported result. ${ }^{26}$ In order to avoid the formation of stereoisomers, we also attempted Baylis-Hillman reaction with formaldehyde, but the reaction rate in aqueous solution seemed too slow to yield the targeted monomer.

\section{Radical Polymerization}

Radical polymerizations of DMDO initiated with AIBN were conducted in toluene or in bulk
(Table 1). The polymerization in toluene afforded polymers soluble in THF and $\mathrm{CHCl}_{3}$ (Run 1). The polymerizations in higher concentration (Run 2) and bulk (Run 3) afforded a larger molecular weight $\left(M_{\mathrm{n}}=18500\right.$ and 27000, respectively) without sacrificing the

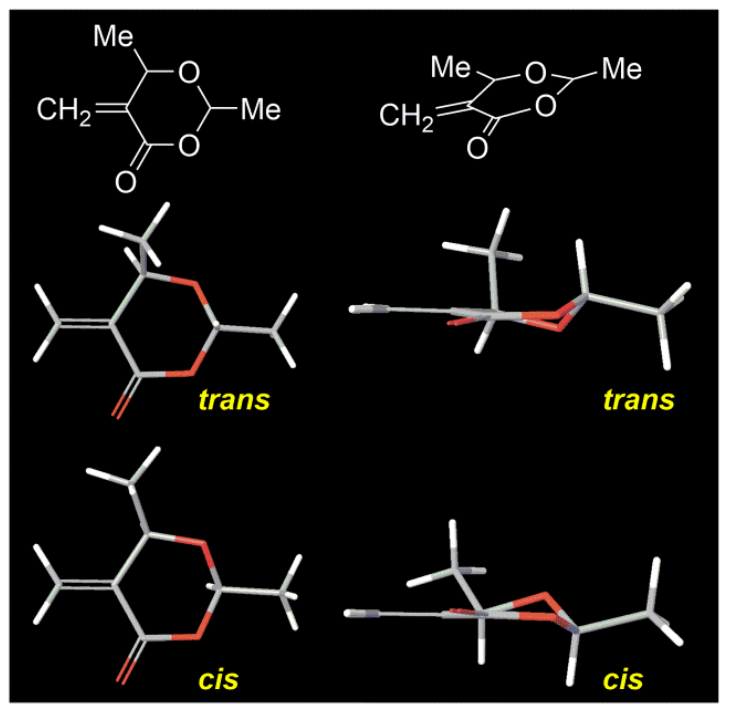

FIGURE 3 The most stable conformations of cisand trans-DMDO predicted by molecular mechanics (Force field: OPLS_2005).

solubility. Although the ${ }^{1} \mathrm{H}$ NMR spectrum of the obtained polymer, P1, was broad, partly due to the two pairs of enantiomers and diastereomers of DMDO (Figure 2a), all ${ }^{1} \mathrm{H}$ signals were assignable to the corresponding monomeric unit, suggesting radical polymerization proceeded without any side 
reactions such as cleavage of the acetal-ester linkage. The $T_{\mathrm{g}}$ of $\mathbf{P 1}$ was observed at $10.1{ }^{\circ} \mathrm{C}$ (Run 1). The much lower $T_{\mathrm{g}}$ than that of common poly(EML)s might be attributed to the more flexible A-E linkage than methylene linkage.

In general, an acrylate which has a branched (secondary or tertiary) $\alpha$-substituent hardly polymerizes because of low ceiling temperature owing to the steric hindrance around vinyl group. $^{31,32}$ In contrast, however, $\alpha$-methylene- $\beta$ methyl- $\gamma$-butyrolactone ( $\beta \mathrm{MMBL}$ ) can polymerize even it has branched $\alpha$-substituent, because (a) the cyclic structure decreasing the steric hindrance around the vinyl group and (b) the higher reactivity of the acrylate moiety fixed cisoid form than that of transoid form. ${ }^{4,7,9,10,12,13}$ The high polymerizability of DMDO, which was found to polymerize even at $110^{\circ} \mathrm{C}$ in bulk (Run $4)$, could be explained for similar reasons. In addition, DMDO has strain in the 6-membered ring due to the 1,3-repulsion of two methyl groups and the planar structure of the acrylate moiety, and thus the conformational change from $\mathrm{sp}^{2}$ carbon (planar) to $\mathrm{sp}^{3}$ carbon (nonplanar) through addition polymerization may afford larger enthalpy gain. This may also attribute the high polymerizability of DMDO.

To investigate the relative reactivities of cis- and trans-isomers, Runs 2-4 were conducted in the presence of bis(trimethylsilyl)acetylene as an internal standard In any case, cis-isomer was consumed faster than trans-isomer. Figure 3 shows the most stable conformations of the two isomers predicted by molecular simulation under OPLS_2005 molecular mechanics. According to the prediction, the dihedral angle of vinyl and carbonyl groups in acrylate moieties in the cis-isomer $\left(2.7^{\circ}\right)$ is smaller than that in the trans-isomer $\left(4.7^{\circ}\right)$. In other words, acrylate moiety in the cis-isomer has more planar, i.e. conjugated structure, which might attribute the higher reactivity in radical polymerization.

\section{Anionic polymerization}

Anionic polymerizations of DMDO were conducted in $\mathrm{CH}_{2} \mathrm{Cl}_{2}$ with isopropyl $\alpha$ lithioisobutyrate $(\mathrm{Li}-i \mathrm{PrIB})^{33}$ as an initiator. The polymerization at $-78{ }^{\circ} \mathrm{C}$ for $18 \mathrm{~h}$ afforded a polymer but in a low yield (Run 5), while that at $0 \quad{ }^{\circ} \mathrm{C}$ afforded almost complete (94\%) conversion (Run 6). The ${ }^{1} \mathrm{H}$ NMR spectrum of the resulting polymer (Figure $2 \mathrm{~b}$ ) was similar to that prepared by radical polymerization (Figure $2 a)$, and the sharp signal assignable to acetal methine group (signal e) was clearly observed with expected intensity, indicating that nucleophilic ring-opening reaction did not occur during the polymerization and thus the cyclic pendants were retained under the anionic polymerization condition.
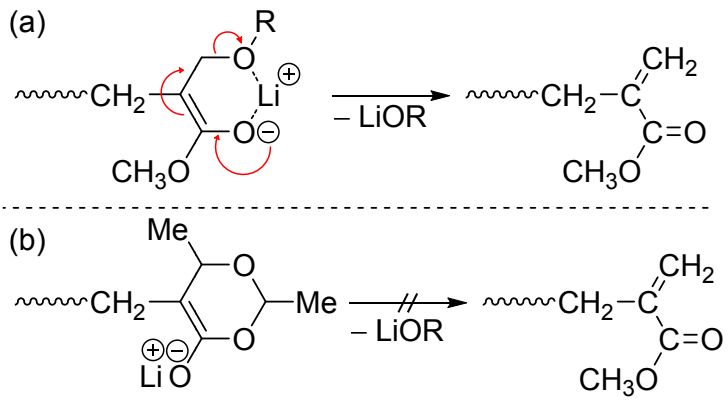

SCHEME 3 Proposed structures of active chainends and their spontaneous terminating reactions in anionic polymerization of (a) $\alpha$ (alkoxymethyl)acrylate and (b) DMDO.

$\alpha$-(Alkoxymethyl)acrylate, acyclic analogues of DMDO, is known to undergo spontaneous termination in anionic polymerization via the elimination of the respective alkoxide anion to afford a polymer with terminal chain-end of an $\alpha, \beta$-unsaturated ester (Scheme 3a). ${ }^{23,34-36}$. The termination dominates over propagation at higher temperature so that the polymerization at $0{ }^{\circ} \mathrm{C}$ does not afford polymeric product. In the case of the polymerization of DMDO, a polymer was obtained at $0{ }^{\circ} \mathrm{C}$ with almost complete conversion (Run 6). Moreover, the ${ }^{1} \mathrm{H}$ NMR spectrum of the polymer did not show any 
vinylidene signals assignable to the $\alpha, \beta$ unsaturated ester chain-end. Since the termination is postulated to proceed through a 6-membered intermediate at the chain-end where two oxygen atoms forms chelatecomplex with the counter cation (Scheme 3a), The high polymerizability of DMDO in the anionic process might be attributed to the A-E linkage (acetal methine carbon atom), which occupies the chelating site between two oxygen atoms and prevents the formation of the intermediate toward termination (Scheme $3 b$ ). The ${ }^{13} \mathrm{C}$ NMR spectra of $\mathbf{P 1}$ prepared from radical and anionic polymerizations are slightly different (See supporting information, Figure $\mathrm{S} 1 \mathrm{~A})$; in particular, the carbonyl signal (Figure $\mathrm{S} 1 \mathrm{~B})$ and the quaternary carbon signal (Figure $\mathrm{S} 1 \mathrm{C})$ shows clear differences. One of the causes of the difference is stereoregularity of the polymers. However, the detailed analysis is hampered since the signal splittings might be caused not only by stereoregularity but also by the monomer sequence of the four isomeric monomers.

Post-polymerization modification by acidhydrolysis

The A-E linkage of P1 was cleaved via acidhydrolysis; P1 was treated with $\mathrm{HCl}$ aq in DMSO- $d_{6}$, and the reaction was monitored with ${ }^{1} \mathrm{H}$ NMR spectra (Figure 4). After $30 \mathrm{~h}$, signals e and $f$ assignable to 6-CH and 6-Me groups on $\mathrm{A}$ E linkage disappeared completely, while new signals A and B of acetaldehyde appeared, suggesting the hydrolysis of A-E linkage. The isolated polymer, P2, afforded the ${ }^{1} \mathrm{H}$ NMR spectrum as expected (Figure 4c). In IR spectra (Figure 5), the carbonyl absorption shifted from $1725 \mathrm{~cm}^{-1}$ to $1735 \mathrm{~cm}^{-1}$ and a new peak assignable to hydroxyl vibration $\left(3433 \mathrm{~cm}^{-1}\right.$ ) was observed after the hydrolysis. These spectral changes confirm the structure of $\mathbf{P} \mathbf{2}$. The solubility drastically changed upon hydrolysis (Table 2); while P1 was soluble in
$\mathrm{CHCl}_{3}, \mathrm{THF}$, and toluene, $\mathbf{P 2}$ was insoluble in these solvents but soluble in DMSO and water, which were poor solvents for P1. $T_{\mathrm{g}}$ increased from $10.1{ }^{\circ} \mathrm{C}$ of $\mathbf{P} \mathbf{1}$ to $21.3^{\circ} \mathrm{C}$ of $\mathbf{P 2}$.

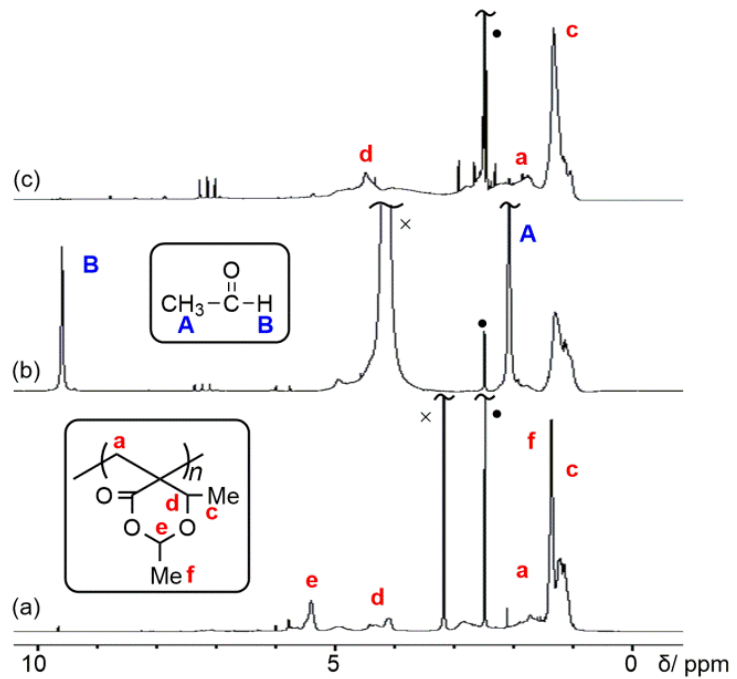

FIGURE $4{ }^{1} \mathrm{H}$ NMR spectra (400 MHz, DMSO- $d_{6}$ ) of (a) P1 $\left(30{ }^{\circ} \mathrm{C}\right)$, (b) the hydrolysis reaction mixture after $30 \mathrm{~h}\left(30^{\circ} \mathrm{C}\right)$, and $(\mathrm{c}) \mathbf{P 2}\left(70^{\circ} \mathrm{C}\right)$. • : DMSO and $\times$ : $\mathrm{H}_{2} \mathrm{O}$.
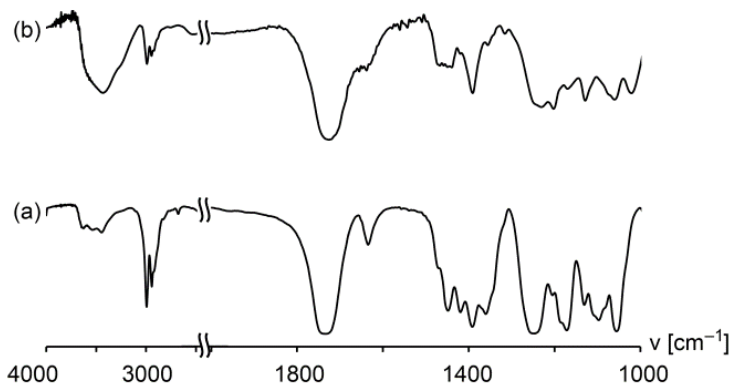

FIGURE 5 IR spectra of (a) P1 and (b) P2.

TABLE 2 Property changes before and after hydrolysis.

\begin{tabular}{|c|c|c|c|c|c|c|}
\hline \multirow[t]{2}{*}{ Polymer } & \multicolumn{5}{|c|}{ Solubility $^{a}$} & \multirow{2}{*}{$\begin{array}{l}T_{\mathrm{g}}^{\mathrm{b}} \\
{\left[{ }^{\circ} \mathrm{C}\right]}\end{array}$} \\
\hline & $\mathrm{CHCl}_{3}$ & THF & Toluene & DMSO & $\mathrm{H}_{2} \mathrm{O}$ & \\
\hline P1 & + & + & + & $+1-$ & - & 10.1 \\
\hline P2 & - & - & - & + & + & 21.3 \\
\hline
\end{tabular}


In the previous work, we have found that the acid-hydrolysis of the polymer of a methoxymethyl acetal-protected $\alpha$ (hydroxymethyl)acrylate prepared by anionic polymerization caused a side reaction, i.e. lactonization between the neighboring two units via ester exchange reaction. ${ }^{23}$ In contrast, P1, the cyclic-acetal protected poly[ $\alpha$ (hydroxymethyl)acrylate], underwent clean deprotection to generate hydrophilic $\alpha$ hydroxymethyl groups together with carboxylic groups, indicating that the cyclic-acetal protection is effective for the protection of $\alpha$ (hydroxymethyl)acrylate derivatives. The corresponding monomer of P2, $\alpha$-(1hydroxyethyl)acrylic acid ( $\alpha \mathrm{HEA}$, see Scheme 1 ) is an acrylate with branched $\alpha$-substituent. As acrylates with branched $\alpha$-substituent are scarcely polymerized ${ }^{31}$ even under high pressure, ${ }^{32}$ aHEA is expected not polymerizable, In fact, there have been no report on the polymerization of $\alpha \mathrm{HEA}$ or its ester derivatives. Thus, it should be notable that this route might be the only way to synthesize $\mathbf{P 2}$.

\section{CONCLUSIONS}

DMDO, a new EML monomer featured by acetal-protected $\quad \alpha$-(alkoxymethyl)acrylate moieties, exhibited distinctively different vinyl polymerization behaviors from acyclic $\alpha$ (alkoxymethyl)acrylate both in radical and anionic polymerization. As the strained 6membered ring increased the reactivity of the vinylidene group, DMDO afforded a vinyl polymer with high monomer conversions even though it has the branched $\alpha$-substituent. In addition, A-E linkage functioned as a barrier to prevent a formation of chelated intermediate toward the spontaneous terminating reaction in anionic polymerization, affording almost complete monomer consumption. Since the hydrolysis of $\mathbf{P} \mathbf{1}$ proceeded efficiently and its properties drastically changed from hydrophobic to hydrophilic, P1 is potentially an acid-responsive polymer or resist materials with the treatments of acid vapor or photoacid generators.

\section{ACKNOWLEDGEMENTS}

The authors would like to thank Iharanikkei Chemical Industry Co. for providing acryloyl chloride. This work was financially supported by Tokuyama Science Foundation (for Y. K.) and Ube Industries Research Foundation: The UBE Foundation (for Y. K.).

\section{REFERENCES AND NOTES}

1. M. K. Akkapeddi, Macromolecules, 1979, 12, 546-551.

2. M. Ueda, M. Takahashi, Y. Imai, C. U. Pittman Jr., J. Polym. Sci.: Polym. Chem. Ed., 1982, 20, 2819-2828.

3. C. U. Pittman Jr., H. Lee, J. Polym.Sci. Part A: Polym. Chem. 2003, 41, 1759-1777.

4. G. Qi, M. Nolan, F. J. Schrok, C. W. Jones, J. Polym. Sci. Part A: Polym. Chem. 2008, 46, 5929-5944.

5. J. Mosnacek, K. Matyjaszewsiki, Macromolecules, 2008, 41, 5509-5511.

6. Y. Higaki, R. Okazaki, A. Takahara, ACS Macro Lett. 2012, 1, 1124-1127.

7. Y.-J. Hu, L. O. Gustafson, H.-P. Zhu, E. Y.X. Chen, J. Polym. Sci. Part A: Polym.

Chem. 2011, 49, 2008-2017.

8. D. Y. Sogah, W. R. Hertler, O. W. Webster, G. M. Cohen, Macromolecules, 1987, 20, 1473-1488.

9. G. M. Miyake, Y. Zhang, E. Y.-X. Chen, Macromolecules, 2010, 43, 4902-4908.

10. Y. Hu, X. Xu, Y. Zhang, Y. Chen, E. Y.-X. Chen, Macromolecules, 2010, 43, 9328-9336.

11. S. Habaue, M. Morita, Y. Okamoto, Polymer, 2002, 43, 3469-3474.

12. X. Chen, L. Caporaso, L. Cavallo, E. Y.-X. Chen, J. Am. Chem. Soc. 2012, 134, 7278-7281.

13. Y. Zhang, E. Y.-X. Chen, Angew. Chem. Int. Ed. 2012, 51, 2465-2469. 
14. Y. Hu, X. Wang, Y. Chen, L. Caporaso, L. Cavallo, E. Y.-X. Chen, Organometallics, 2013, 32, 1459-1465.

15. O. Stöhr, H. Ritter, Macromol. Chem. Phys. 2014, 215, 426-430.

16. M. Hong, E.Y.-X. Chen, Macromolecules, 2014, 47, 3614-3624

17. S. Habaue, M. Asai, M. Morita, Y. Okamoto, H. Uyama, S. Kobayashi, Polymer, 2003, 44, 5195.

18. H. Uyama, S. Kobayashi, M. Morita, S. Habaue, Y. Okamoto, Macromolecules, 2001, 34, 6554-6556.

19. Y. Kohsaka, T. Kurata, T. Kitayama, Polym. Chem. 2013, 4, 5043-5047.

20. Y. Kohsaka, T. Kurata, K. Yamamoto, S. Ishihara, T. Kitayama, Polym. Chem. 2015, 6, 1078-1087.

21. Y. Kohsaka, K. Yamamoto, T. Kitayama, Polym. Chem. 2015, 6, 3601-3607.

22. Y. Kohsaka, S. Ishihara, T. Kitayama, Macromol. Chem. Phys. accepted for publication.

23. Y. Kohsaka, K. Suzawa, T. Kitayama, Macromol. Symp. 2015, 350, 86-98.

24. Y. Kohsaka, E.Yamaguchi, T. Kitayama, J. Polym. Sci. Part A: Polym. Chem., 2014, 52, 2806-2814..

25. Y. Kohsaka, Y. Matsumoto, T. Kitayama, Polym. Chem. 2015, 6, 5026-5029.
26. P. Perlmutter, E. Puniani, G. Westman, Tetrahed. Lett. 1996, 37, 1715-1718.

27. W.-D. Lee, K.-S. Yang, K. Chen, Chem. Commun. 2001, 37, 1612-1613.

28. H. Otsuka, H. Fujiwara, T. Endo, J. Polym. Sci. Part A: Polym. Chem. 1999, 37, 4478-4482.

29. H. Otsuka, H. Fujiwara, T. Endo, React. Funct. Polym. 2001, 46, 293-298.

30. H. Otsuka, T. Endo, Macromolecules, 1999, 32, 9059-9061.

31. K. Chikanishi, T. Tsuruta, Makromol. Chem. 1965, 81, 211-222.

32. J. Rzayev, J. Penelle, J. Polym. Sci. Part A: Polym. Chem. 2002, 40, 836-843.

33. T. Kitaura, T. Kitayama, Macromol. Rapid Commun. 2007, 28, 1889-1893.

34. S. Habaue, H. Yamada, Y. Okamoto, Macromolecules, 1996, 29, 3326-3327.

35. S. Habaue, H. Yamada, T. Uno, Y. Okamoto, J. Polym. Sci., Part A: Polym. Chem. 1997, 35, 721-726.

36. Y. Okamoto, S. Habaue, T. Uno, H. Baraki, Macromol. Symp. 2000, 157, 209-216. 


\section{GRAPHICAL ABSTRACT}

Yasuhiro Kohsaka, Yusuke Matsumoto, Tianyi Zhang, Tatsuki Kitayama

$\alpha$-Exomethylene lactone possessing acetal-ester linkage: Polymerization and post-polymerization modification for water-soluble polymer

2,6-Dimethyl-5-methylene-1,3-dioxa-4-one, a novel trifunctional monomer with acrylate, ester, and acetal moieties in a 6-membered ring, was prepared from the Baylis-Hillman reaction of an aryl acrylate. The radical and anionic polymerization with azo and ester enolate initiators, respectively, afforded the corresponding vinyl polymers, which were converted to water-soluble polymers bearing hydroxyl and carboxy pendants via the acid hydrolysis of the acetal-ester linkage. The polymerization characteristics are also discussed through the comparison with respective acyclic monomers.

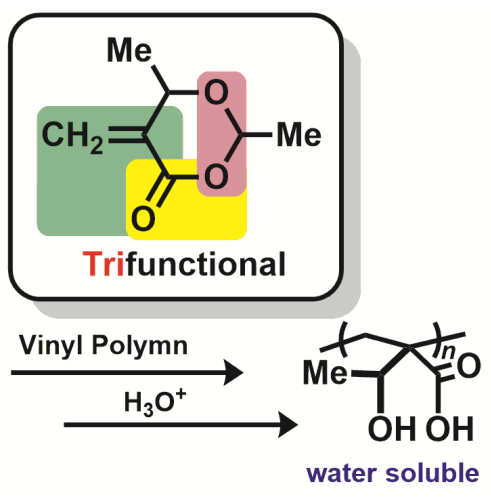

